\title{
Caracterização farmacobotânica das espécies de Sambucus (Caprifoliaceae) utilizadas como medicinais no Brasil. Parte I. Sambucus nigra L.
}

\author{
Marina Scopel $^{1 *}$, Eliana Nunes ${ }^{2}$, Márcia Vignoli-Silva², Giovana S. Vendruscolo², \\ Amélia T. Henriques ${ }^{1}$, Lilian A. Mentz ${ }^{2}$ \\ ${ }^{1}$ Faculdade de Farmácia, Departamento de Farmacognosia, Universidade Federal do Rio Grande do Sul, Av. \\ Ipiranga, 2752, 90610-000, Porto Alegre, RS, Brasil, \\ ${ }^{2}$ Departamento de Botânica, Universidade Federal do Rio Grande do Sul, Av. Bento Gonçalves, 9500, Prédio \\ 43433, Campus do Vale, 91501-970, Porto Alegre, RS, Brasil
}

\begin{abstract}
RESUMO: O sabugueiro (Sambucus nigra L., Caprifoliaceae) é uma planta medicinal descrita em farmacopéias estrangeiras, não constando da Farmacopéia Brasileira. A espécie é de origem européia e suas flores são comercializadas in natura sob o nome farmacopéico Sambuci flos, para uso na forma de infusão ou decocção, como diuréticas, antipiréticas, antiinflamatórias, laxativo leve e no tratamento de doenças do aparelho respiratório. Visando elaborar uma monografia farmacopéica atualizada, foram estabelecidos os caracteres botânicos macro e microscópicos, através da metodologia clássica utilizada em morfoanatomia vegetal. São características macroscópicas: flores monoclinas, iguais; corola de três a cinco milímetros de diâmetro; pétalas com três a quatro nervuras paralelas; estames iguais; gineceu em regra com três lóculos. São características microscópicas: cutícula espessa e estriada; presença de idioblastos de areia cristalina de oxalato de cálcio em brácteas, sépalas e pétalas; estômatos anomocíticos; brácteas hipoestomáticas; sépalas anfiestomáticas; pétalas anfi-hipoestomáticas; células epidérmicas da face abaxial de sépalas e pétalas muito sinuosas; células epidérmicas do filete alongadas e de paredes retilíneas; tricomas tectores e glandulares de diferentes tipos em todas as peças; brácteas, sépalas e pétalas com mesofilo homogêneo; sistema vascular representado por feixes colaterais ou agrupamentos de elementos xilemáticos; presença de gotas lipídicas em todas as peças.
\end{abstract}

Unitermos: Sambucus nigra, Caprifoliaceae, farmacobotânica, morfoanatomia.

\begin{abstract}
Pharmacobotany characterization of Sambucus species (Caprifoliaceae), used in traditional medicine in Brazil. Part I. Sambucus nigra L.”. The Elder tree (Sambucus nigra L., Caprifoliaceae) is a medicinal plant described in international pharmacopoeias, not yet mentioned in the Brazilian Pharmacopoeia. The flowers of this European species are commercialized in natura by the pharmacopeial name of Sambuci flos, with diuretic, antipyretic, anti-inflammatory and mild laxative purposes, and to treat respiratory diseases, through infusions or decoctions forms. Aiming at elaborating an updated pharmacopeial monograph, the macro and microscopic botanic characters were established, with the classic methodology used in plant morpho-anatomy. The macroscopic characters are: monoclin and equal flowers; corolla with three to five millimeters of diameter; petals with three to four parallel veins; equal stamens; ovary often with three locules. The main microscopic characters are: thickened and striated cuticle; anomocytic stomatas; bracts, sepals and petals with sandy crystals of calcium oxalate idioblasts; hypostomatic bracts; amphystomatic sepals; amphi-hypostomatic petals; strongly wavy epidermal cells in the lower surface of sepals and petals; filaments epidermal cells with narrow and straight walls; glandular and non-glandular trichomes of different types in all pieces; homogeneous mesophyll in bracts, sepals and petals; vascular system represented by both collateral bundles and xylematic elements; volatile and nonvolatile oil globules in all structures.
\end{abstract}

Keywords: Sambucus nigra, Caprifoliaceae, pharmacobotany, morpho-anatomy.

\section{INTRODUÇÃO}

A família Caprifoliaceae(sensulato)compreende 18 gêneros e 450 espécies, distribuídas principalmente nas regiões temperadas do Hemisfério Norte (Europa, América do Norte, oeste e centro da Ásia, e norte da África), com uma menor distribuição no Hemisfério Sul (Heywood, 1993). O único gênero com espécies nativas 
na América do Sul é Sambucus, com duas espécies (Dimitri, 1980): Sambucus peruviana Kunth, que ocorre no nordeste da Argentina, na Região Andina da América do Sul, na América Central até o México; e Sambucus australis Cham. \& Schltdl., que ocorre no Brasil da Região Sudeste até o Rio Grande do Sul, Paraguai, Argentina e Uruguai (Bacigalupo, 1974; Reitz, 1985). Os demais gêneros encontrados no país foram introduzidos e são atualmente cultivados (Abelia, Lonicera e Viburnum), ou esporadicamente assilvestrados (Reitz, 1985; Barroso, 1986). Autores recentes sugerem que o gênero Sambucus seja realocado para a família Sambucaceae (Takhtajan, 1997), ou para Adoxaceae (Judd et al., 1999), enquanto outros ampliam a circunscrição de Caprifoliaceae (APG II, 2003).

O gênero Sambucus possui cerca de 25 espécies (Reitz, 1985). Entre estas, destacam-se Sambucus canadensis L. (American Elder), Sambucus ebulus L. (Dwarf Elder), Sambucus nigra L. (Black Elder, European Elder, sabugueiro) e Sambucus australis Cham. \& Schltdl. (sabugueiro-do-rio-grande, sabugueiro-dobrasil), mencionadas como espécies medicinais em suas regiões de origem (Tôrres et al., 2005; Agra et al., 2007). Sambucus nigra está descrita em diversas farmacopéias estrangeiras, como Alemã, Austríaca, Francesa, Holandesa, Húngara, Portuguesa, Suíça, Européia, etc., não constando de nenhuma edição da Farmacopéia Brasileira. A espécie é de origem européia (Atkinson; Atkinson, 2002) e suas flores são comercializadas in natura sob o nome farmacopéico Sambuci flos (Czygan et al., 2001), para uso na forma de infusão ou decocção, como diuréticas, antipiréticas, antiinflamatórias, laxativo leve e no tratamento de doenças do aparelho respiratório (Rebuelta et al., 1983; Mascolo et al., 1987; Czygan et al., 2001; Newall et al., 2002). Estudo experimental in vitro mostrou que o extrato etanólico do caule inibiu a enzima acetilcolinesterase (Barbosa-Filho et al., 2006a). Morronisideo, um iridóide isolado das folhas desta mesma planta mostrou-se inativo no ensaio da enzima conversora de angiotensina (Barbosa-Filho et al., 2006b).

Sambucus nigra é uma árvore ou arbusto muito ramificado, de até 7,0 m de altura, de copa globosa. As folhas são pecioladas, opostas, imparipinadas, compostas de 3 a 7 (raro até 11) folíolos elípticos, fracamente assimétricos, membranosos, de 5,0 a $12,0 \mathrm{~cm}$ de comprimento, finamente dentados na margem, agudos no ápice, glabros. As estípulas são sésseis e, geralmente, caducas. As flores são amareladas ou brancas, pequenas, dispostas em amplas cimeiras corimbosas terminais, monoclinas, diclamídeas, pentâmeras ou tetrâmeras, actinomorfas. $\mathrm{O}$ androceu é formado por quatro ou cinco estames epipétalos, de tamanhos iguais e o gineceu, em regra, por três carpelos soldados entre si, com três lóculos e três rudimentos seminais, de placentação axial. Em algumas inflorescências ocorre predominância de flores tetrâmeras. O fruto é negro, elíptico, com cerca de 7,0 mm de diâmetro (Perrot, 1944; Planchon et al., 1946,
Paris; Moyse, 1971; Dimitri, 1980; British, 1996; Czygan et al., 2001; WHO, 2001; Atkinson; Atkinson, 2002).

\section{MATERIAL E MÉTODOS}

Para a análise de Sambucus nigra foram adquiridas 03 amostras de flores secas, no comércio de Porto Alegre (RS) e, 10 amostras de flores secas foram fornecidas pelo laboratório de Farmacognosia da Faculdade de Farmácia da Universidade Federal do Rio Grande do Sul, totalizando 13 amostras, datadas de 2001 à 2004. O material foi identificado utilizando-se como caráter o número de lóculos no ovário, predominantemente três. Para a análise macroscópica a matéria-prima passou por um processo de hidratação, tendo as observações sido realizadas em microscópio estereoscópico Wild, modelo M5A. As ilustrações foram feitas com câmara clara acoplada a um microscópio estereoscópico Também foram analisados macroscopicamente os possíveis contaminantes presentes nas amostras que, de acordo com os compêndios europeus (European Pharmacopoea, 2002; Farmacopéia Portuguesa, 2002), para Sambucus nigra, podem ser pedicelos grosseiros e flores de coloração castanha. As peças florais, além do pedicelo, foram seccionadas transversalmente, tangencialmente e paradermicamente, a mão livre. Foram confeccionadas lâminas semi-permanentes em gelatina glicerinada e observadas ao microscópio óptico Olympus, modelo CB. As amostras adquiridas foram pulverizadas e analizadas ao microscópio óptico, com a adição de hidrato de cloral. Foram realizados alguns testes histoquímicos, empregando-se as metodologias de detecção de lipídios, com Sudan IV (Sass, 1951; Gerlach, 1984) e amido, utilizando-se o reativo de Lugol (Foster, 1949), sugeridas por Argüeso (1986), Farmacopéia Brasileira 4 ed. (1988), Kraus \& Arduin (1997), WHO (1998), Farias (2002), de celulose, com azul de toluidina (Gerlach, 1984) e de lignina, utilizando-se fluroglucina (Sass, 1951). Para o estabelecimento do padrão de venação foi utilizada a técnica de diafanização segundo Argüeso (1986) e Kraus \& Arduin (1997).

\section{RESULTADOS}

A análise macroscópica e microscópica das flores de Sambucus nigra L., resultou em uma descrição de todas as suas estruturas, servindo de base para o estabelecimento de padrões de controle farmacobotânico da matéria-prima.

\section{Análise macroscópica}

As flores secas, amareladas pela dessecação, são pentâmeras ou tetrâmeras, diclamídeas, gamopétalas, actinomorfas, com 3,0 a 5,0 mm de diâmetro, completas, monoclinas, todas iguais (Fig. 1-A e 1-B) e apresentam, cada uma delas, até três diminutas brácteas, distribuídas 
uma ou duas na base do cálice e uma ou duas no corpo do pedicelo, ou uma no receptáculo e duas no corpo do pedicelo em diferentes alturas, ou todas ao longo do pedicelo em diferentes alturas, visíveis com lente de aumento; de coloração verde e com variadas formas, como elípticas (Fig. 1-G1, a-e) a obovado-elípticas (Fig. 1-G5, a-b), oblongas (Fig. 1-G2), laminares (Fig. 1-G3) ou triangulares (Fig. 1-G4), pouco papilosas. Estas peças medem 0,6 a 1,5 mm de comprimento e 0,5 mm de largura e possuem tricomas tectores (Fig. 1-G1, c), distribuídos por toda a lâmina ou restritos a margem basal da face adaxial e tricomas glandulares (Fig. 1-G1, b), ambos os tipos com ampla variabilidade de formas. Apresentam também dentes marginais unicelulares (Fig.1-G1, a). Os botões florais são globosos, em todos os estágios de desenvolvimento, esbranquiçados ou amarronzados, medindo 1,5 a 3,0 mm de diâmetro. O cálice é formado por sépalas esbranquiçado-amareladas, esverdeadas ou amarronzadas, triangulares (Fig. 1-E), que medem 0,5 a $1,2 \mathrm{~mm}$ de comprimento e 0,5 a $0,7 \mathrm{~mm}$ de largura na porção basal, sendo levemente soldadas entre si na base. Estas peças apresentam dentes marginais unicelulares e tricomas tectores distribuídos na margem e na base da face adaxial, onde também foram observados tricomas glandulares, de variados tipos, visíveis com lente de aumento. A corola é rotada (Fig. 1-A), branco-amarelada a amarelo-claro, de pré-floração imbricada, com pétalas soldadas entre si na base em um curto tubo. As pétalas são ovaladas a elípticas (Fig. 1-A e 1-C), de ápice retrorso, arredondado, medindo 2,0 a $3,5 \mathrm{~mm}$ de comprimento e 2,0 a 3,0 mm de largura. A corola desprende-se com facilidade e apresenta aspecto de estrela (Fig. 1-C) com filetes aderidos. Tricomas tectores e glandulares de diferentes formas ocorrem na porção basal de ambas as faces, sendo que a maior densidade é verificada na face adaxial. $\mathrm{O}$ androceu é formado por quatro ou cinco estames, dispostos alternadamente às pétalas (Fig. 1-A), com filetes aderidos ao tubo da corola. As anteras (Fig. 1F) são ditecas, extrorsas, dorsifixas, oblongas, deiscentes, de coloração amarela, com 1,0 mm de comprimento. Os filetes são glabros e cilíndricos e medem de 1,0 a 1,5 mm de comprimento. A flor possui ovário ínfero, soldado ao tubo calicino, tricarpelar, raro tetracarpelar, trilocular, raro tetralocular, com carpelos bem demarcados nas flores secas, com um rudimento seminal por lóculo, de placentação axial. O gineceu é globoso e papiloso (Fig. 1-D), com um curto estilete e estigma trilobado. Os lobos estigmáticos são obtusos e apresentam três proeminências cada um. Um disco anelado e proeminente envolve a base do gineceu.

\section{Análise microscópica}

Brácteas: Em vista frontal, a cutícula é estriada e as estrias acompanham o eixo maior das células epidérmicas (Fig. 2-A e Fig. 2-B). As células epidérmicas fundamentais são alongadas, de diferentes formas, com núcleos evidentes e com algumas gotas lipídicas esféricas. Na região do bordo e sobre a região da nervura principal estas células apresentam forma tabular e são mais alongadas e de paredes retilíneas. Tricomas tectores (Fig. 2-F1, a-c e Fig. 2-F2, a-c) e glandulares (Fig. 2-F3, a-z), muito variados, são observados por toda a lâmina, com maior densidade na base da face adaxial. Raros idioblastos de areia cristalina, de oxalato de cálcio, de aspecto enegrecido e sem forma definida, são visíveis. As brácteas são hipoestomáticas, com estômatos do tipo anomocítico (Fig. 2-B). Em secção transversal, a cutícula é bastante espessa e estriada (Fig. 2-D e Fig. 2-E). Os estômatos localizam-se no mesmo nível das demais células epidérmicas. A constituição do mesofilo é de até quatro camadas de clorênquima, geralmente três, com células isodiamétricas, reduzidos espaços intercelulares e na região da nervura principal há redução do número de cloroplastídios. O sistema vascular geralmente é composto por um único agrupamento xilemático (Fig. 2D), o qual pode estar envolto por bainha parenquimática simples, sem ou com poucos cloroplastídios. Gotas lipídicas esféricas ocorrem em todos os tecidos (Fig. 2-D e Fig. 2-E), exceto no xilema.

Receptáculo: Em vista frontal, a cutícula é estriada. As estrias epicuticulares acompanham o eixo maior das células epidérmicas, as quais possuem forma tabular e/ou quadrangular, paredes retilíneas, núcleo evidente e gotas lipídicas esféricas e constituem uma única camada celular. Em secção transversal, o receptáculo apresenta forma circular, com cutícula espessa e bastante estriada. O tecido parenquimático é formado por células isodiamétricas, de pequeno volume, com reduzidos espaços intercelulares e poucos cloroplastídios, formando até doze camadas celulares. Este tecido, próximo ao lóculo, possui células com menor volume (Fig. 5-E). Os feixes vasculares são do tipo colateral e distribuem-se em forma de anel pelo tecido parenquimático (Fig. 5-D). Gotas lipídicas esféricas ocorrem em todos os tecidos (Fig. 5-E).

Cálice: Cada sépala, quando diafanizada, mostra uma a três nervuras paralelas, a principal chega até o ápice e ramifica-se, as outras duas ramificam-se na região mediana ou acompanham a nervura principal até o ápice, mantendo o paralelismo. As sépalas são anfiestomáticas, com estômatos do tipo anomocítico (Fig. 3-A e Fig. 3B). Em vista frontal, a cutícula é intensamente estriada e as estrias dispõem-se paralelamente ao eixo maior das células fundamentais da epiderme (Fig. 3-A e Fig. 3-B). Estas células apresentam forma tabular, paredes retilíneas na face adaxial e retilíneas a sinuosas na face abaxial, núcleos evidentes e comumente gotas lipídicas esféricas. A face abaxial mostra estriação cuticular mais intensa. Na região basal de ambas as faces, com maior densidade na face adaxial, distribuem-se os tricomas tectores (Fig. 3E1, a-f e Fig. 3-E2, a-h) e glandulares (Fig. 3-E3, a-g), de diferentes formas. Os tricomas tectores ocorrem também na região da margem e são comumente encontrados 
na porção basal, entre as sépalas. Idioblastos de areia cristalina, de oxalato de cálcio, de aspecto enegrecido e sem forma definida são visíveis em ambas as faces. Em secção transversal (Fig. 3-D), a cutícula é bastante estriada e espessa, principalmente na região dos bordos. Aepiderme é uniestratificada e constituída por células com paredes retilíneas, de forma poligonal, achatadas tangencialmente na face adaxial e de forma poligonal na face abaxial. O mesofilo é homogêneo, formado por até cinco camadas de células clorenquimáticas, isodiamétricas, com poucos cloroplastídios, com amplos espaços intercelulares (Fig. 3-D) e com esparsos idioblastos de areia cristalina. O sistema vascular está representado por um a três agrupamentos xilemáticos (Fig. 3-C), com até cinco elementos traqueais de espessamento helicoidal cada um (Fig. 3-D). Nas células parenquimáticas do xilema ocorrem grãos de amido elipsóides e, envolvendo o agrupamento xilemático principal, é visível uma bainha parenquimática simples, com cloroplastídios. Na região do bordo o parênquima apresenta-se frouxo e na extremidade desta região geralmente ocorre uma única camada de células parenquimáticas. Gotas lipídicas esféricas ocorrem em todos os tecidos.

Corola: Cada pétala, quando diafanizada, mostra geralmente, três, raro quatro nervuras paralelas, sendo que as secundárias partem da principal, ramificadas ou não, nunca anastomosadas no ápice (Fig. 1-C). Na porção basal de ambas as faces ocorrem tricomas tectores (Fig. 4-F1) e glandulares (Fig. 4-F2, a-f), de diferentes formas, sendo que a maior densidade ocorre na face adaxial. As pétalas são anfi-hipoestomáticas, com estômatos do tipo anomocítico (Fig. 4-B). Em vista frontal, a cutícula é mais estriada na face abaxial (Fig. 4-B), e menos estriada na face adaxial. Idioblastos de areia cristalina, de oxalato de cálcio, de aspecto enegrecido e sem forma definida, são visíveis em ambas as faces (Fig. 4-C). Em secção transversal, a cutícula é espessa e estriada na face abaxial e mais espessa e menos estriada na face adaxial (Fig. 4-E). A epiderme é uniestratificada, com células fundamentais poligonais e isodiamétricas, papilosas e de paredes anticlinais espessas, retilíneas na face adaxial, com pontoações e núcleos evidentes. Na região da nervura principal estas células podem apresentar forma tabular. Na face abaxial, as células epidérmicas fundamentais são alongadas, de maior volume do que as da face adaxial, exceto na região da nervura principal, de paredes muito sinuosas e delgadas. Em ambas as faces ocorrem pequenas gotas lipídicas. O mesofilo é homogêneo, formado por até dez camadas de clorênquima frouxo, com células de forma irregular, núcleos evidentes e poucos cloroplastídios (Fig. 4-E). Por vezes, ocorrem amplos espaços intercelulares. O sistema vascular está representado por três a seis feixes vasculares colaterais igualmente desenvolvidos (Fig. 4D), distribuídos pelo parênquima, com maior quantidade de elementos xilemáticos do que floemáticos, podendo estar envolvidos por bainha parenquimática simples. $\mathrm{Na}$ região do bordo, o sistema vascular é formado apenas por agrupamentos de elementos xilemáticos. Grãos de amido elipsóides estão presentes nos parênquimas.

Androceu: O filete, em vista frontal, possui cutícula estriada e as estrias acompanham o eixo maior das células epidérmicas, as quais são alongadas, possuem forma retangular, paredes retilíneas e delgadas, núcleo evidente e poucas gotas lipídicas (Fig. 4-G). Em secção transversal (Fig. 4-H e 4-I), o filete apresenta forma circular, possui cutícula delgada e finamente estriada. A epiderme é uniestratificada, formada por células epidérmicas poligonais e os estômatos são ausentes. O parênquima é formado por células poligonais de diferentes dimensões, que diminuem de volume em direção ao centro, frouxo, desprovido de cloroplastídios e com poucas gotas lipídicas. O sistema vascular preenche a região central (Fig. 4-I) e é formado por elementos traqueais de espessamento helicoidal. A antera, em secção transversal (Fig. 5-A), possui epiderme bastante papilosa. O tapete é formado por uma única camada de células achatadas tangencialmente e o endotécio por duas a três camadas de células de forma trapezoidal, fibrosas, com pontoações evidentes. O parênquima é pouco frouxo. O grão de pólen é prolato, tricolporado, com 15 a $25 \mu \mathrm{m}$ de diâmetro; superfície reticulada, em vista polar arredondado (Fig. 5-B, b) e em vista equatorial, elipsoidal (Fig. 5-B, a).

Gineceu: O gineceu, em seç̧ão transversal, apresenta, em geral, três carpelos, raro quatro, cada um de forma triangular a triangular-ovalada. Cada cavidade apresenta um rudimento seminal, de forma ovalada a elíptica (Fig. 5-D). Numerosas gotas lipídicas e grande quantidade de grãos de amido tornam-se evidentes no tecido parenquimático das paredes carpelares, somente quando utilizado corante (Fig. 5-E). Os feixes vasculares estão distribuídos no tecido parenquimático e geralmente seu número corresponde ao número de lóculos, com disposição oposta a estes. O tecido parenquimático é compacto, com células pequenas, isodiamétricas, com cloroplastídios e gotas lipídicas. Observa-se que a quantidade de cloroplastídios diminui significativamente na região central do ovário. O tecido que reveste o lóculo (Fig. 5-E) é formado por células achatadas tangencialmente, sem espaços intercelulares e com núcleo evidente quando utilizado lugol. $\mathrm{O}$ tecido adjacente ao que forma a parede carpelar apresenta até três camadas de células justapostas, alongadas, compactas, com grande quantidade de grãos de amido, sem cloroplastídios e com espessamento parietal evidente em todas as paredes. Gotas lipídicas ocorrem em todos os tecidos. As células epidérmicas do estigma são extremamente papilosas.

\section{Descrição macroscópica dos contaminantes}

De acordo com o determinado pelos compêndios europeus (European Pharmacopoea, 2002; Farmacopeia Portuguesa, 2002), os materiais considerados estranhos nas amostras de flores de Sambucus nigra são os pedicelos 
da própria espécie. Em geral, estes se apresentam esbranquiçados pela dessecação, longitudinalmente sulcados, medindo 1,0 a 7,0 mm de comprimento e $1,0 \mathrm{~mm}$ ou mais de espessura, com tricomas tectores distribuídos por toda a sua extensão ou somente na região basal, onde também ocorrem tricomas glandulares, visíveis com lente de aumento.

\section{Descrição microscópica dos contaminantes}

Em vista frontal, o pedicelo apresenta ornamentação cuticular evidente (Fig. 5-F), com estrias paralelas ao eixo maior das células epidérmicas. Estas células são alongadas e retangulares, de paredes retilíneas espessadas e comumente possuem gotas lipídicas. Os estômatos são do tipo anomocítico (Fig. 5-F). Na porção basal ocorrem tricomas tectores (Fig. 6-A1, a-b e 6-A2, a-e) e glandulares (Fig. 6-A3, a-c), de várias formas. Em secção transversal, o pedicelo apresenta forma irregular, com proeminências e reentrâncias muito acentuadas (Fig. 5-G). A cutícula é espessa e estriada. A epiderme é uniestratificada, com células fundamentais de forma tabular e de paredes periclinais internas espessas. A região cortical externa é composta por colênquima tabular subepidérmico, distribuído em uma a seis camadas, apresentando poucos cloroplastídios, além de um parênquima com amplos espaços intercelulares e poucos cloroplastídios. Na região cortical interna, as células parenquimáticas apresentam maior volume e raros cloroplastídios (Fig. 5-H). O sistema vascular é envolvido por uma camada endodérmica e apresenta até dezesseis feixes vasculares colaterais, dispostos em forma de anel, em grau de desenvolvimento variável (Fig. 5-G). Nos feixes de maior desenvolvimento ocorre uma calota de fibras calibrosas, externamente ao floema, enquanto que o xilema apresenta, externamente, fibras pouco desenvolvidas. O câmbio interfascicular, por vezes, é evidente. Nos pedicelos em estágio de desenvolvimento secundário, há expressão do tecido xilemático. A região medular é reduzida e preenchida por parênquima com células de grande volume, paredes delgadas e poucos cloroplastídios. Gotas lipídicas ocorrem na epiderme e no parênquima cortical. Grãos de amido são observados na endoderme e no floema.

\section{Descrição microscópica do pó}

São característicos para o pó das flores de Sambucus nigra: coloração amarelo-esverdeada; fragmentos de sépalas com dentes marginais unicelulares isolados (Fig. 6-B3, a-c); fragmentos de epiderme de sépalas e pétalas papilosas e com cutícula estriada (Fig. 6-B1, a-g); fragmentos de epiderme com estômatos anomocíticos (Fig. 6-B1, f); células-guarda isoladas (Fig. 6-B2); fragmentos de epiderme com tricomas tectores de diferentes tipos; raros tricomas tectores (Fig. 6-B4, a-c) e glandulares (Fig. 6-B5, a-b) isolados ou partes destes;

fragmentos de parênquima (Fig. 6-B7); porções de tecidos com gotas lipídicas; parte de elementos traqueais de espessamento anelar e helicoidal (Fig. 6-B9); fragmentos da epiderme de antera, extremamente papilosa (Fig. 6B8, a-b); fragmentos da camada fibrosa de antera (Fig. 6B10); numerosos grãos de pólen como descritos; grãos de pólen isolados (Fig. 6-B11, a) ou agrupados (Fig. 6-B11, b), ou associados a fragmentos de anteras e de epiderme de diversas peças (Fig. 6-B8); porções de estigma com epiderme papilosa; porções de brácteas; porções do bordo de sépalas, de pétalas (Fig. 6-B6) e de brácteas.

\section{DISCUSSÃO}

As características estruturais evidenciadas através da análise macroscópica são semelhantes às informações encontradas na literatura (Mansfield, 1937; Gilg et al., 1942; Yougken, 1950; Coimbra, 1958; Bacigalupo, 1974; Correa, 1984; British, 1996; PDR, 1998; Simões et al., 1998; D’Amelio, 1999; Jorge et al., 1999; WHO, 2001; Atkinson; Atkinson, 2002). Gilg et al. (1942) também constataram o desprendimento da corola e sua aparência enrugada quando seca. Entretanto, os autores não informam a ocorrência de tricomas na face adaxial das sépalas, caracterizando-as como glabras e descrevem os tricomas tectores da face abaxial como pequenos e unicelulares, enquanto que a pilosidade foi observada em ambas as faces no presente estudo, assim como tricomas tectores pluricelulares e glandulares de diferentes formas. A ampla variabilidade constatada nestas estruturas sugere que tal característica deva ser considerada como de valor taxonômico e as representações das mesmas são inéditas, uma vez que não são encontradas na bibliografia específica para o gênero. A Farmacopéia Herbária Britânica (British, 1996) e a OMS (WHO, 2001) confirmam as características dos dentes marginais presentes nas sépalas, o que também denota valor taxonômico para esta estrutura. Gilg et al. (1942) confirmam a ocorrência das três bractéolas, porém em diferente localização. A descrição dos grãos de pólen confere com aquela mencionada em Gilg et al. (1942). No entanto, na Farmacopéia Herbária Britânica (British, 1996) e na OMS (WHO, 2001), os grãos são referidos como de forma subesférica, enquanto Nair (1961) os refere com a forma esferoidal. A tipologia da ornamentação cuticular confere com a relatada por Eschrich (1988), Farmacopéia Herbária Britânica (British, 1996) e OMS (WHO, 2001). A maior intensidade da estriação na face abaxial, tanto em sépalas quanto em pétalas (British, 1996; Jorge et al., 1999; WHO, 2001) foi confirmada. A análise da sinuosidade das células epidérmicas da face abaxial das sépalas e pétalas confere com o relatado pela Farmacopéia Herbária Britânica (British, 1996) e pela OMS (WHO, 2001). A presença de gotas de óleo em diferentes tecidos é uma característica relevante para a espécie, também relatado por Eschrich (1988), pela Farmacopéia Herbária Britânica (British, 1996) e OMS 


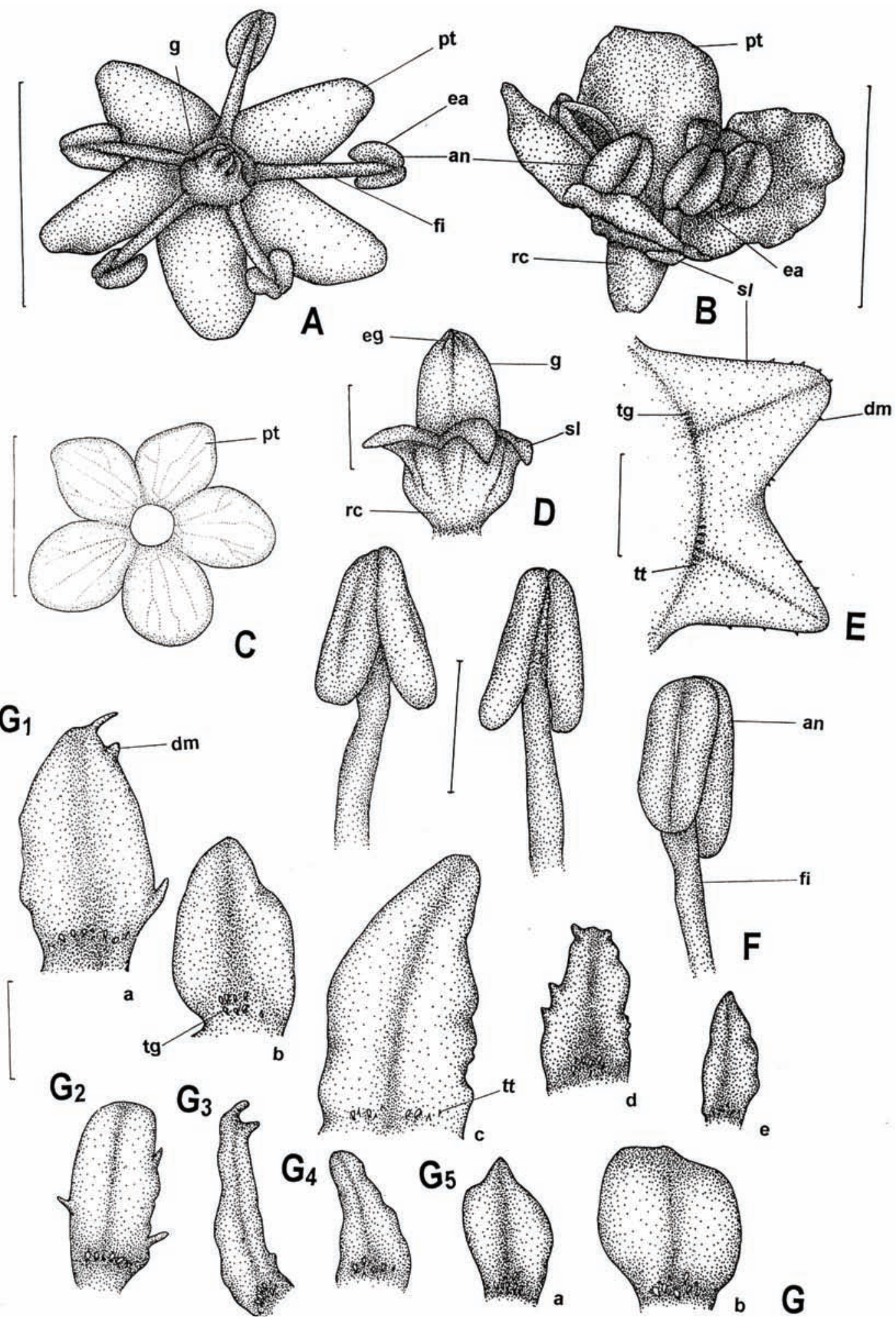

Figura 1. Sambucus nigra L. - detalhe macroscópico das peças florais. A. aspecto geral da flor, em vista frontal; an: antera; ea: estame; fi: filete; g: gineceu; pt: pétala; B. aspecto geral da flor, em vista lateral; an: antera; ea: estame; pt: pétala; rc: receptáculo; sl: sépala; C. aspecto geral da corola desprendida, em vista frontal; pt: pétala; D. aspecto geral do gineceu, do receptáculo e do cálice, em vista lateral: eg: estigma; g: gineceu; rc: receptáculo; sl: sépala; E. aspecto geral de parte do cálice, em vista frontal; dm: dente marginal; sl: sépala; tg: tricoma glandular; tt: tricoma tector F. aspectos gerais de estames em diferentes posições laterais; an: antera; fi: filete; G. aspectos gerais da face adaxial de brácteas, em vista frontal, evidenciando suas distintas formas; G1. a-e: brácteas elípticas; G2. bráctea oblonga; G3. bráctea laminar; G4. bráctea triangular; G5. a-b brácteas obovado-elípticas; dm: dente marginal; tg: tricoma glandular; tt: tricoma tector. As réguas correspondem em A e B a 3,0 mm; em $\mathbf{C}$ a 5,0 mm, em $\mathbf{D}$ e $\mathbf{E}$ a 1,0 $\mathrm{mm}$; em $\mathbf{F}$ a $0,5 \mathrm{~mm}$; $\mathbf{G}$ a $0,4 \mathrm{~mm}$. 


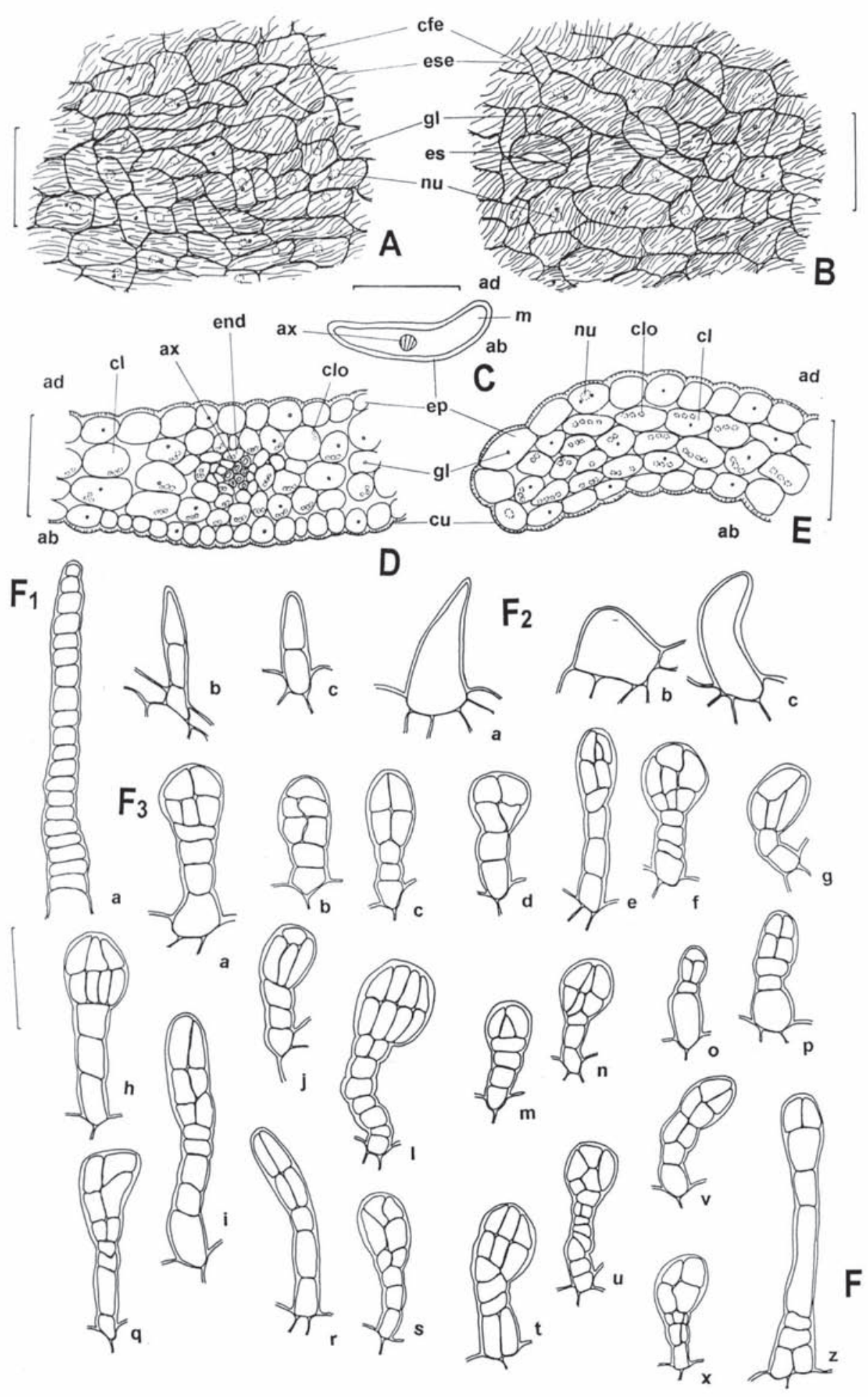

Figura 2. Sambucus nigra L. - detalhes microscópicos de brácteas. A. detalhe de porção da face adaxial da epiderme da bráctea, em vista frontal; cfe: célula fundamental da epiderme; ese: estrias epicuticulares; gl: gota lipídica; nu: núcleo; B. detalhe de porção da face abaxial da epiderme de bráctea, em vista frontal; cfe: célula fundamental da epiderme; es: estômato; ese: estrias epicuticulares; gl: gota lipídica; nu: núcleo; C. esquema geral da bráctea, em secção transversal; ab: face abaxial; ad: face adaxial; ax: agrupamento xilemático; ep: epiderme; m: mesofilo; D. detalhe da região da nervura principal, da bráctea, em secção transversal; ab: face abaxial; ad: face adaxial; ax: agrupamento xilemático; end: endoderme; cl: clorênquima; clo: cloroplastídio; cu: cutícula; ep: epiderme; gl: gota lipídica; x: xilema; E. detalhe de porção da região do bordo, da bráctea, em secção transversal; ab: face abaxial; ad: face adaxial; cl: clorênquima; clo: cloroplastídio; cu: cutícula estriada; ep: epiderme; gl: gota lipídica; nu: núcleo; F. detalhe de tricomas ocorrentes em brácteas. F1. a-c: tricomas tectores pluricelulares unisseriados; F2. a-c: tricomas tectores unicelulares; F3. a-z: tricomas glandulares com cabeça pluricelular. As réguas correspondem em $\mathbf{A}, \mathbf{B}$ e $\mathbf{D}-\mathbf{F}$ a $100 \mu \mathrm{m}$; em $\mathbf{C}$ a 0,4 mm. 

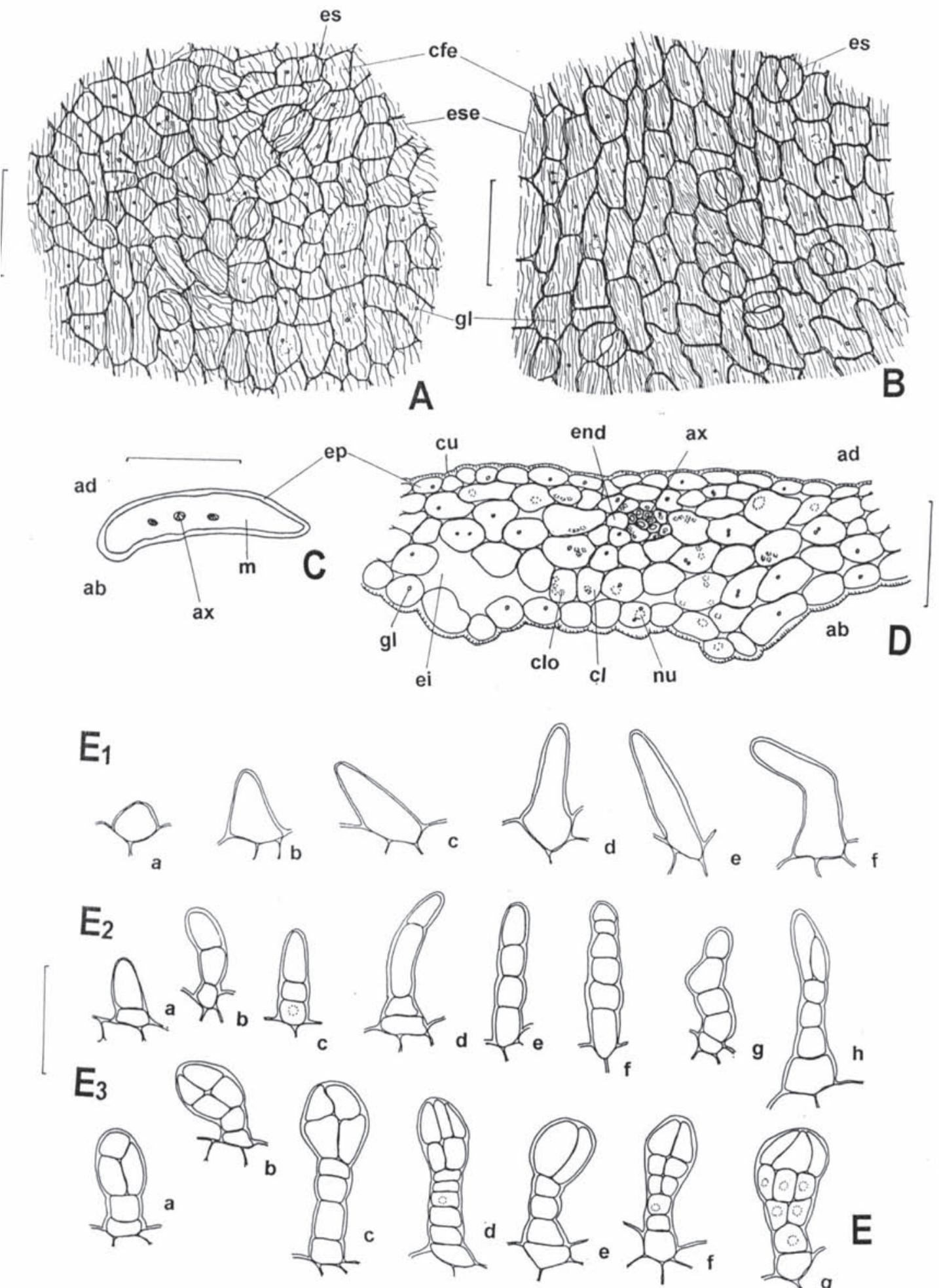

Figura 3. Sambucus nigra L. - detalhes microscópicos de sépalas. A. detalhe de porção da face adaxial da epiderme da sépala, em vista frontal; cfe: célula fundamental da epiderme; es: estômato; ese: estrias epicuticulares; gl: gota lipídica; B. detalhe de porção da face abaxial da epiderme da sépala, em vista frontal; cfe: célula fundamental da epiderme; es: estômato; ese: estrias epicuticulares; gl: gota lipídica; C. esquema geral da sépala, em secção transversal; ab: face abaxial; ad: face adaxial; ax: agrupamento xilemático; ep: epiderme; m: mesofilo; D. detalhe de porção da sépala na região da nervura principal, em secção transversal; ab: face abaxial; ad: face adaxial; ax: agrupamento xilemático; end: endoderme; cl: clorênquima; clo: cloroplastídio; cu: cutícula estriada; ei: espaço intercelular; ep: epiderme; gl: gota lipídica; nu: núcleo; E. detalhe de tricomas ocorrentes em sépalas. E1. a-f: tricomas tectores unicelulares; E2. a-h: tricomas tectores pluricelulares unisseriados; E3. a-g: tricomas glandulares com cabeça pluricelular. As réguas correspondem em $\mathbf{A}, \mathbf{B}, \mathbf{D}$ e $\mathbf{E}$ a $100 \mu \mathrm{m}$; em $\mathbf{C}$ a 0,4 mm. 

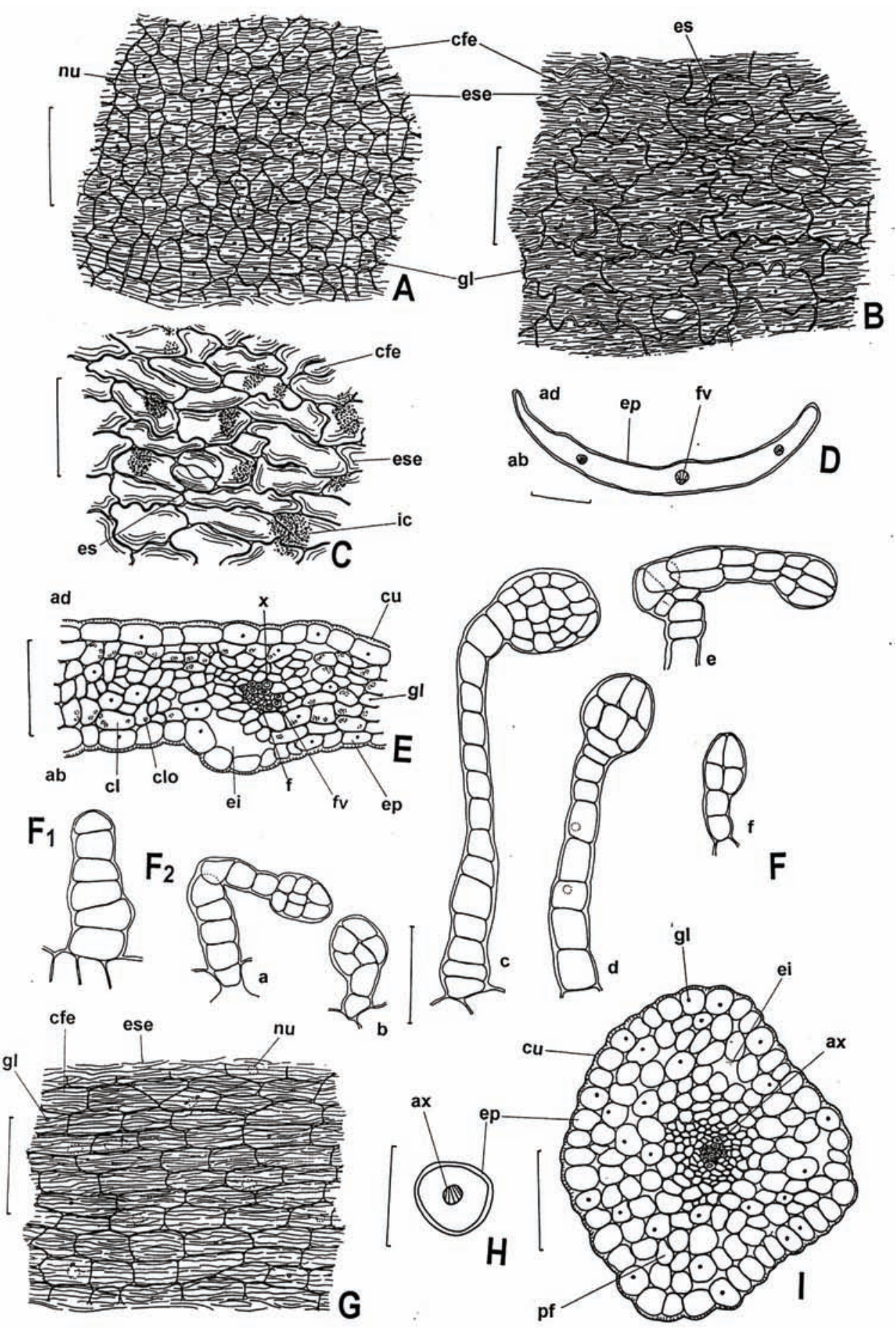

Figura 4. Sambucus nigra L. - detalhes microscópicos de pétalas e filetes. A. detalhe de porção da face adaxial da epiderme da pétala, em vista frontal; cfe: célula fundamental da epiderme; ese: estrias epicuticulares; gl: gota lipídica; nu: núcleo; B. detalhe de porção da face abaxial da epiderme da pétala, em vista frontal; cfe: célula fundamental da epiderme; es: estômato; ese: estrias epicuticulares; gl: gota lipídica; $\mathbf{C}$. detalhe de porção da face abaxial da epiderme da pétala, em vista frontal; cfe: célula fundamental da epiderme; es: estômato; ese: estrias epicuticulares; ic: idioblasto cristalífero; D. esquema geral da pétala, em secção transversal; ab: face abaxial; ad: face adaxial; ep: epiderme; fv: feixe vascular; m: mesofilo; E. detalhe de porção da pétala, na região da nervura principal, em secção transversal; ab: face abaxial; ad: face adaxial; cl: clorênquima; clo: cloroplastídio; cu: cutícula estriada; ei: espaço intercelular; ep: epiderme; f: floema; fv: feixe vascular; gl: gota lipídica; x: xilema; F. detalhe de tricomas ocorrentes em pétalas; F1. tricoma tector pluricelular unisseriado; F2. a-f: tricomas glandulares com cabeça pluricelular; G. detalhe de porção da epiderme do filete, em vista frontal; cfe: célula fundamental da epiderme; ese: estrias epicuticulares; gl: gota lipídica; nu: núcleo; H. esquema geral do filete, em secção transversal; ax: agrupamento xilemático; ep: epiderme; I. detalhe do filete em secção transversal; ax: agrupamento xilemático; cu: cutícula estriada; ei: espaço intercelular; ep: epiderme; gl: gota lipídica; p: parênquima. As réguas correspondem em A - C, E - G e I a $100 \mu \mathrm{m}$; em D e H a 0,4 mm. 

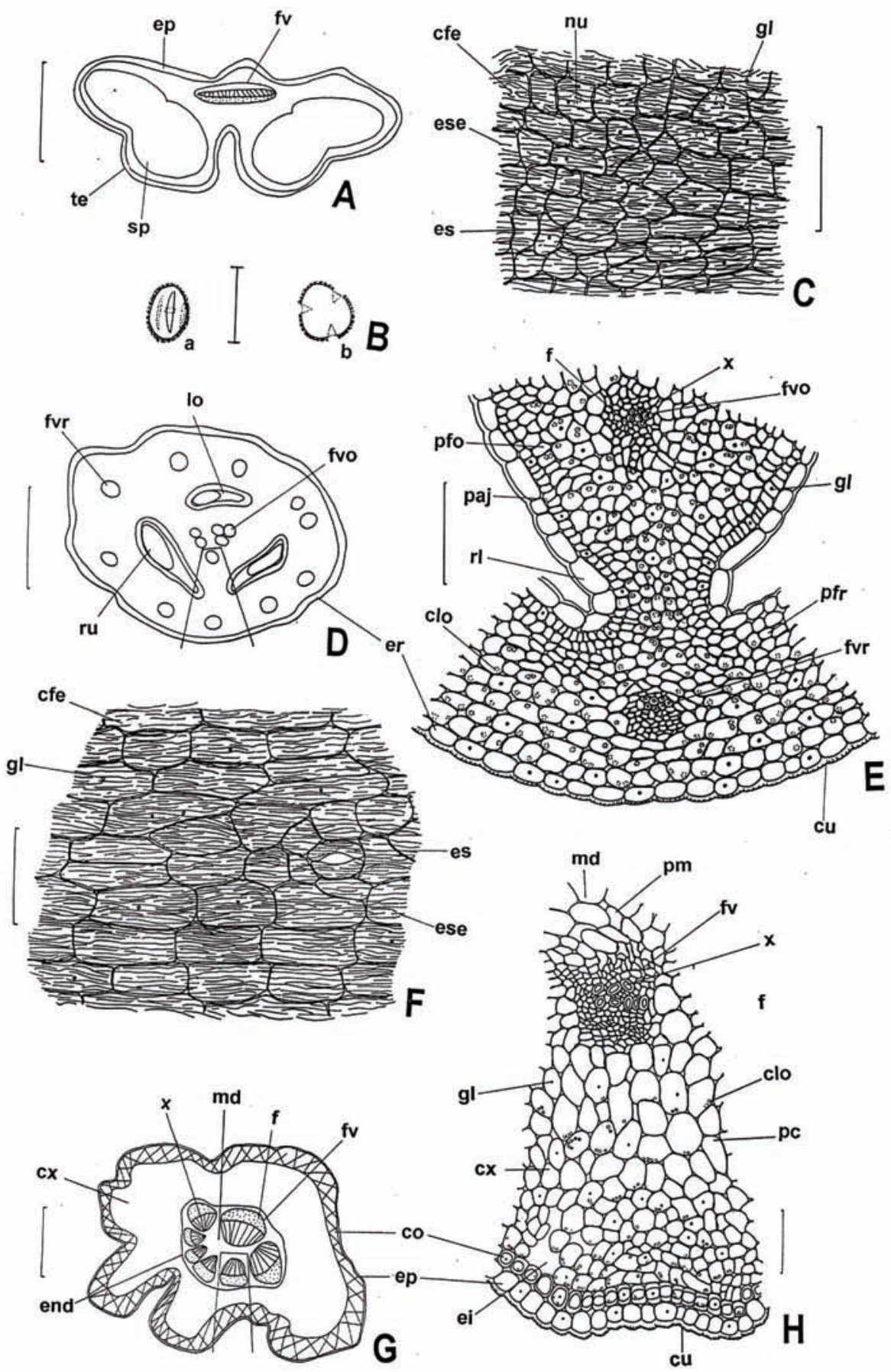

Figura 5. Sambucus nigra L. - detalhes microscópicos de antera, receptáculo, ovário e pedicelo. A. esquema geral da antera, em secção transversal; ep: epiderme; fv: feixe vascular; sp: saco polínico; te: teca; B. esquema geral do grão de pólen; a: vista polar; b: vista equatorial. C. detalhe de porção da epiderme do receptáculo, em vista frontal; cfe: célula fundamental da epiderme; es: estômato; ese: estrias epicuticulares; gl: gota lipídica; nu: núcleo; D. esquema geral do receptáculo e do ovário em secção transversal; er: epiderme do receptáculo; fvo: feixe vascular do ovário; fvr: feixe vascular do receptáculo; lo: lóculo; ru: rudimento seminal; E. detalhe de porção do receptáculo e do ovário, em secção transversal; clo: cloroplastídios; cu: cutícula estriada; er: epiderme do receptáculo; f: floema; fvo: feixe vascular do ovário; fvr: feixe vascular do receptáculo; gl: gota lipídica; paj: parênquima de células justapostas; po: parênquima do ovário; pr: parênquima do receptáculo; rl: revestimento do lóculo; x: xilema; F. detalhe de porção da epiderme do pedicelo, em vista frontal; cfe: célula fundamental da epiderme; es: estômato; ese: estrias epicuticulares; gl: gota lipídica; G. esquema geral do pedicelo em secção transversal; co: colênquima; cx: córtex; end: endoderme; ep: epiderme; f: floema; fv: feixe vascular; md: medula; x: xilema; H. detalhe de porção do pedicelo em secção transversal; clo: cloroplastídio; co: colênquima; cu: cutícula estriada; cx: córtex; ei: espaço intercelular; ep: epiderme; f: floema; fv: feixe vascular; gl: gota lipídica; md: medula; pc: parênquima cortical; pm: parênquima medular; x: xilema. As réguas correspondem em A, D e G a $400 \mu \mathrm{m}$; em C, E, F e $\mathbf{H}$ a $100 \mu \mathrm{m}$; em $\mathbf{B}$ a $30 \mu \mathrm{m}$. 


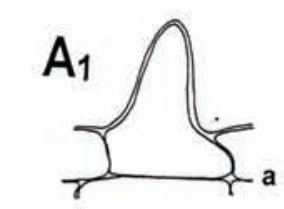

$\mathrm{A}_{2}$
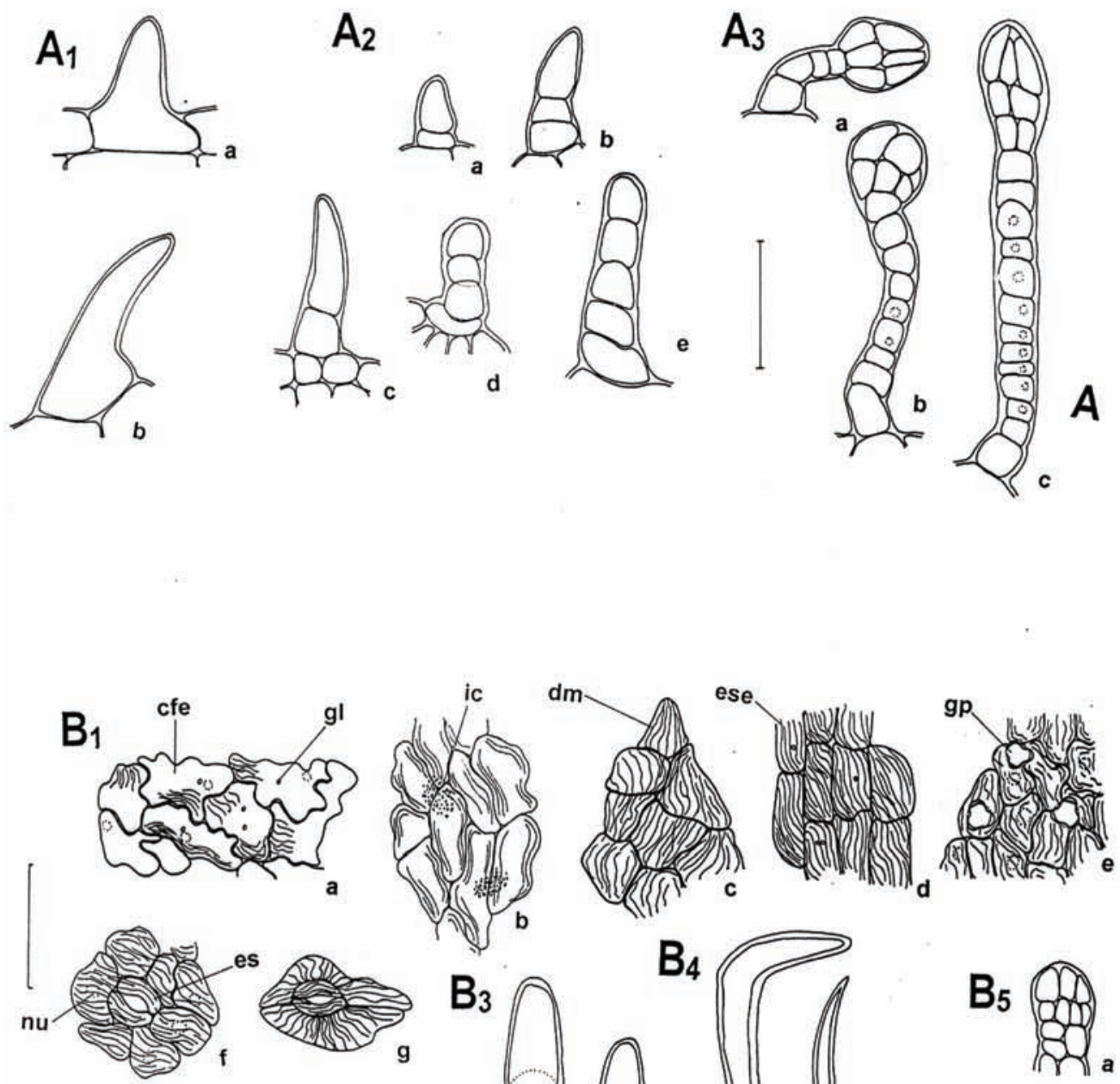

$B_{3}$

$\mathrm{B}_{4}$

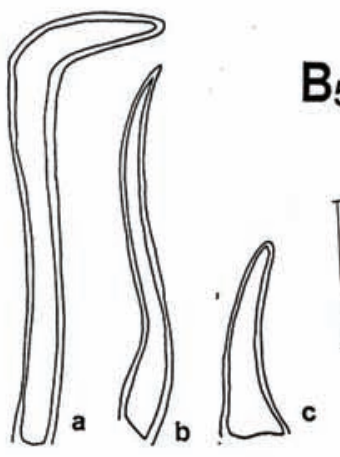

5

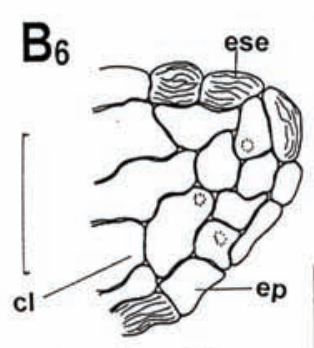

$B_{2}$<smiles>[Te][Te]</smiles><smiles>C1=CC2CCC1C2</smiles>
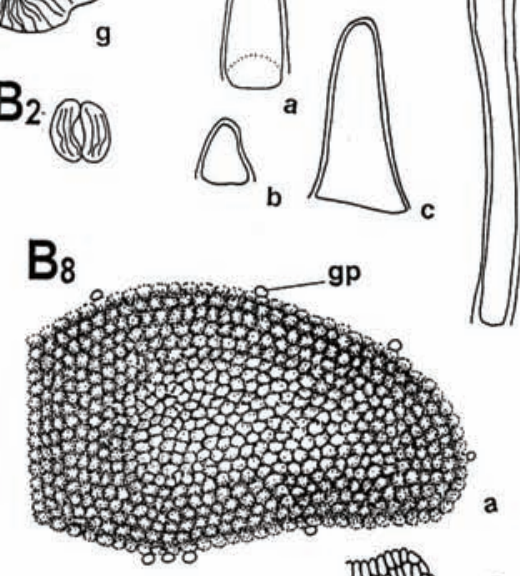

$B_{9}$
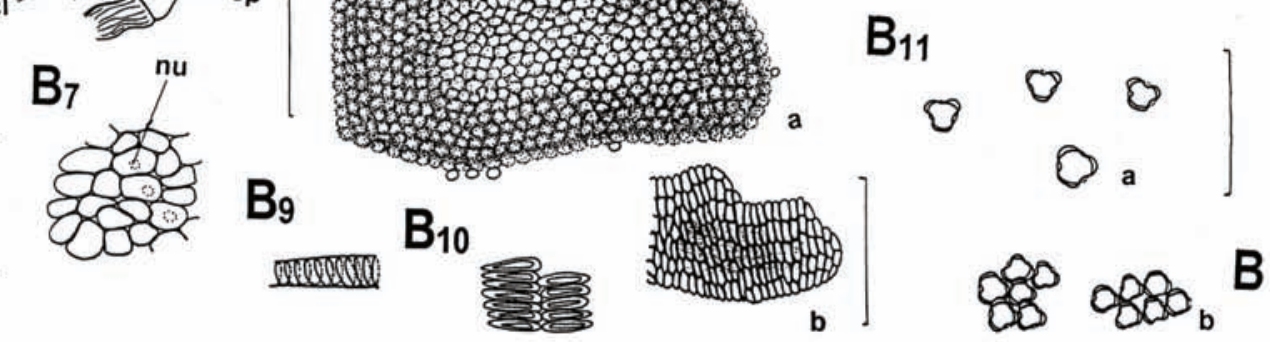

Figura 6. Sambucus nigra L. - detalhes microscópicos de pedicelo e pó. A. detalhe de tricomas ocorrentes no pedicelo; A1. a-b: tricomas tectores unicelulares; A2. a-e: tricomas tectores pluricelulares unisseriados; A3. a-c: tricomas glandulares com cabeça pluricelular; B. detalhes do pó. B1. a-g: fragmentos de epiderme; cfe: célula fundamental da epiderme; dm: dente marginal; es: estômato; ese: estrias epicuticulares; gl: gota lipídica; gp: grão de pólen; ic: idioblasto cristalífero; nu: núcleo; B2. células-guarda isoladas; B3. a-c: porções de dentes marginais; B4. a-c: porções de tricomas tectores unicelulares; B5. a-b: porções de tricomas glandulares com cabeça pluricelular; B6. porção de bordo da pétala; ep: epiderme; ese: estrias epicuticulares; cl: clorênquima; nu: núcleo; B7. fragmento de parênquima; nu: núcleo; B8. fragmentos da antera; a. porção convexa; b. porção côncava; gp: grão de pólen; B9. porção de elemento traqueal com espessamento parietal helicoidal; B10. fragmento da camada fibrosa da antera; B11. grãos de pólen; a. isolados; b. agrupados. As réguas correspondem em A e B (B1 - B7 e B9 - B11) e $100 \mu$ m; em B (B8) a 400 $\mu \mathrm{m}$. 
(WHO, 2001). A tipologia dos estômatos é confirmada pela Farmacopéia Herbária Britânica (British, 1996) e OMS (WHO, 2001). No entanto, a literatura não informa sobre a ocorrência de estômatos na face adaxial das peças florais, considerando a espécie como hipoestomática. Somente Atkinson \& Atkinson (2002) informam a rara ocorrência de estômatos na face adaxial do pecíolo de $S$. nigra. A presença de cristais de areia de oxalato de cálcio foi observada somente em vista frontal em brácteas, pétalas e sépalas, sendo que nas últimas encontramse esparsamente distribuídas no mesofilo. Entretanto, Eschrich (1988), Farmacopéia Herbária Britânica (1996) e OMS (WHO, 2001) referem os cristais presentes exclusivamente no mesofilo de sépalas e pétalas. A camada fibrosa da antera com paredes espessas e com pontoações evidentes também foi mencionada pela Farmacopéia Herbária Britânica (British, 1996) e pela OMS (WHO, 2001).

A coloração do pó, a presença de grãos de pólen, de cristais de areia de oxalato de cálcio e dentes marginais em porções de sépalas, além da ornamentação cuticular de células epidérmicas conferem com as características referidas pela OMS (WHO, 2001).

\section{AGRADECIMENTOS}

Os autores agradecem à CAPES e à Farmacopéia Brasileira pelo suporte financeiro. Este trabalho é parte da dissertação de mestrado de Marina Scopel.

\section{REFERÊNCIAS}

Agra MF, França PF, Barbosa-Filho JM 2007. Synopsis of the plants known as medicinal and poisonous in Northeast of Brazil. Rev Bras Farmacogn 17: 114-140.

Barbosa-Filho JM, Medeiros KCP, Diniz MFFM, Batista LM, Athayde-Filho PF, Silva MS, Cunha EVL, Almeida JRGS, Quintans-Júnior LJ 2006a. Natural products inhibitors of the enzyme acetylcholinesterase. Rev Bras Farmacogn 16: 258-285.

Barbosa-Filho JM, Martins VKM, Rabelo LA, Moura MD, Silva MS, Cunha EVL, Souza MFV, Almeida RN, Medeiros IA 2006b. Natural products inhibitors of the angiotensin converting enzyme (ACE). A review between 1980-2000. Rev Bras Farmacogn 16: 421446.

APG II 2003. The Angiosperm Phylogeny Group. An Update of the angiosperm phylogeny group classification for the orders and families of flowering plants: APG II. Bot $J$ Linn Soc 441: 399-436.

Argüeso AA 1986. Manual de Tecnicas en Histologia Vegetal. Buenos Aires: Hemisferio Sur.

Atkinson MD, Atkinson E 2002. Biological Flora of the British isles - Sambucus nigra L. n. 225. J Ecol 98: 895-923.

Bacigalupo NM 1974. Caprifoliaceae. In: Burkart, A. Flora Ilustrada de Entre Rios (Argentina). Buenos Aires: INTA, v.6, pt.6, p.50-52.
Barroso GM 1986. Sistemática das Angiospermas. Viçosa: Imprensa Universitária UFV. v.3.

British Herbal Pharmacopoeia 1996. 4.ed. Londres: BHMA.

Coimbra R 1958. Notas de Fitoterapia: Catálogos dos Dados Principais sobre Plantas Uutilizadas em Medicina e Farmácia. Rio de Janeiro: Arte Moderna.

Correa PM 1984. Dicionário de Plantas Úteis do Brasil e das Exóticas Cultivadas. Rio de Janeiro: IBDF, v.6.

Czygan F-C, Frohne F, Höltzel C, Nogell A, Pfänder HJ, Willthun G, Buff W 2001. Sambuci Flos. In: Bisset, N.G.; Wichtl, M. (Ed) Herbal Drugs and Phytopharmaceuticals: A Handbook for Pratice on a Cientific Basis. 2.ed. Stuttgart: Scientific Publishers CRC, p.446-448.

D’Amelio FS 1999. Botanicals: A Phytocosmetic Desk Reference Boca Raton: CRC Press.

Dimitri MJ 1980. Enciclopedia Argentina de Agricultura y Jardineria. 3.ed. Buenos Aires: ACME v.2.

Eschrich W 1988. Pulver Atlas der Drogen des Deutschen Arzneibuches. Stuttgart: Fischer.

European Pharmacopoea 2002. 4.ed. Strasbourg: Council of Europe.

Farias MR 2002. Avaliação da qualidade de matérias-primas vegetais. In:Simões, C.M.O.; Schenkel, E.P.; Gosmann, G.; Mello, J.C.P.; Mentz, L.A.; Petrovick, P.R. (Ed.) Farmacognosia - da Planta ao Medicamento. 4.ed. Porto Alegre / Florianópolis : Ed. da UFRGS / Ed. da UFSC, p.199-222.

Farmacopéia Brasileira 1988. 4.ed. São Paulo: Atheneu.

Farmacopeia Portuguesa 2002. 7.ed. Lisboa : Ministério da Saúde.(cd-rom)

Foster AS 1949. Pratical Plant Anatomy. Princeton: van Nostrand.

Gerlach D 1984. Botanische Microtechnik. Stuttgart: Georg Thieme.

Gilg E, Brandt W, Schürhoft PN 1942. Farmacognosia: Matéria Farmacêutica Vegetal y Animal. 2.ed. Barcelona: Labor.

Heywood VH 1993 (Ed). Flowering Plants of the World. Nova Iorque: Oxford University Press.

Jorge LIF, Graciano RAS, Prado SPT, Pereira U 1999. Identificação histológica de Sambucus australis Cham. \& Schlecht. (Sabugueiro). Rev Ciênc Farm 20: 117-123.

Judd WS, Campbell CS, Kellog EA, Stevens PF 1999. Plant Systematics: a Phylogenetic Approach. Massachusetts: Sinauer Associates.

Kraus JE, Arduin M 1997. Manual Básico de Métodos em Morfologia Vegetal. Seropédica. Rio de Janeiro: EDUR.

Mascolo N, Autore G, Capasso F, Menghini A, Fasulo MP 1987. Biological screening of Italian medicinal plants for anti-inflammatory activity. Phytother Res 1: 28-31.

Masnfield W 1937. Matéria Medica, Toxicology and Pharmacognosy.Saint Louis:CVM.

Nair PKK 1960. Pollen morphology of some Indian medicinal plants. J Sci Ind Res 20c: 45-50. 
Newall CA, Anderson LA, Phillipson JD 2002. Plantas Medicinais - Guia para o Profissional de Saúde. Londres: Pharmaceutical Press.

Paris RR, Moyse H 1971. Précis de Matiére Médicale. Paris: Masson. v.3.

PDR for Herbal Medicines 1998. Montvale: Medical Economics.

Perrot EN 1944. Matières Premières Usuelles du Règne Vegetal: Thérapeutique, Hygiène, Industrie. Paris: Masson. v.2.

Planchon L, Bretin P, Maneau P 1946. Précis de Matiere Mèdicale. 50.ed. Paris: Librarie Maloine. v.2.

Rebuelta M, Vivas JM, San Roman L, Fernandez MGS 1983. Étude de l’effet diurétique de différents préparations des fleurs du Sambucus nigra. Plantes Médicinales et Phytothérapie 17: 173-181.

Reitz R 1985. Caprifoliáceas. In: Flora Ilustrada Catarinense. Itajaí. Fasc. CAPR.

Sass JE 1951. Elements of Botanical Microtechnique. Nova Iorque: McGraw-Hill.

Simões CMO, Mentz LA, Schenkel EP, Irgang BE, Stchmann JR 1998. Plantas da Medicina Popular no Rio Grande do Sul. Porto Alegre: UFRGS.

Tôrres AR, Oliveira RAG, Diniz MFFM, Araújo EC 2005. Estudo sobre o uso de plantas medicinais em crianças hospitalizadas da cidade de João Pessoa: riscos e benefícios. Rev Bras Farmacogn 15: 373-380.

Takhtajan AL 1997. Diversity and Classification of Flowering Plants. Nova Iorque: Columbia University Press.

WHO 1998. World Health Organization - Quality Control Methods for Medicinal Plant Materials. Geneva: WHO.

WHO 2001. World Health Organization - Monographs on Selected Medicinal Plants. Genebra: WHO, v.2.

Yougken HW 1950. Textbook of Pharmacognosy. 6.ed. Filadélfia: Blakiston. 